\title{
Membrane Microviscosity Is Increased in the
}

\section{Erythrocytes of Patients with}

\section{Adrenoleukodystrophy and Adrenomyeloneuropathy}

\author{
R. A. Knazek, W. B. Rizzo, J. D. Schulman, and J. R. Dave, Laboratory of \\ Pathophysiology, National Cancer Institute and Section on Biochemical \\ Genetics, Developmental Pharmacology Branch, National Institute of \\ Child Health and Human Development, National Institutes of Health, \\ Bethesda, Maryland 20205
}

A B S T R A C T Adrenoleukodystrophy (ALD) and adrenomyeloneuropathy $(\mathrm{AMN})$ are related $\mathrm{X}$-linked disorders characterized by adrenal, gonadal, and nervous system dysfunction. While the pathologic finding common to these tissues appears to be the accumulation of excessive amounts of very long chain fatty acids, the mechanism leading to functional impairment in these tissues is unclear.

Measurements of fluorescence polarization $(P)$, using the lipid probe diphenylhexatriene, demonstrate a highly significant increase in the microviscosity of erythrocyte membranes in affected patients ( $P$ $=0.286 \pm 0.012)$ vs. normals $(P=0.239 \pm 0.020)$. Analyses of these membranes by gas-liquid chromatography revealed 1.9-, 1.6-, and 1.3-fold increases above normal values in the C25:0, C26:0, and C27:0 fatty acids, respectively.

These observations are compatible with previously obtained data in animals that correlate membrane microviscosity with the number of hormone receptors in target tissues. The present data support the thesis that a decrease in responsiveness to trophic hormones in ALD and AMN is secondary to changes in the membrane microviscosity of the target tissues and suggest a mechanism by which adrenal and gonadal failure occur in such patients.

This work was presented in part at the Meeting for the American Society of Clinical Investigation, Washington, DC, May, 1982.

Dr. Rizzo's (Department of Pediatrics) and Dr. Dave's (Department of Physiology) current address is Medical College of Virginia, Richmond, VA 23298; Dr. Schulman's address is Department of Obstetrics and Gynecology, George Washington University, Washington, DC.

Received for publication 4 February 1983.

\section{INTRODUCTION}

Adrenoleukodystrophy (ALD) ${ }^{1}$ and the less acute variant, adrenomyeloneuropathy (AMN), are inherited Xlinked diseases in which central nervous system demyelination or peripheral nerve dysfunction is associated with primary adrenal insufficiency. Most male patients with AMN also have hypogonadism (1-4).

Cytoplasmic trilamellar structures, presumed morphologic evidence of lipid accumulation, have been observed in brain, peripheral nerves, testes, and adrenal cortex $(1,3,5)$. Recent studies have demonstrated that these tissues $(6-8)$ and skin fibroblasts $(9,10)$ cultured from patients having either disease accumulate long-chain saturated fatty acids, especially hexacosanoic acid (C26:0). Hexacosanoic acid has also been reported to be increased in erythrocyte sphingomyelin (11) and in the plasma (12) of patients with ALD.

A unifying mechanism by which these abnormalities in lipid metabolism cause adrenal, and, in some cases, testicular failure, is unclear. We present evidence that ALD and AMN are accompanied by an alteration in erythrocyte membrane microviscosity that could reflect abnormalities seen within both the nervous and endocrine systems of affected patients. The measurement of membrane microviscosity within circulating erythrocytes also provides a discriminant that can be used rapidly and simply to differentiate affected from nonaffected individuals.

\section{METHODS}

All patients were diagnosed as having ALD or AMN on the basis of clinically detectable central nervous system or pe-

\footnotetext{
${ }^{1}$ Abbreviations used in this paper: ALD, adrenoleukodystrophy; AMN, adrenomyeloneuropathy; DPH, 1,6-diphenylhexatriene; $P$, fluorescence polarization.
} 
ripheral nerve dysfunction, inadequate responses to cortrosyn (ACTH) stimulation, and pronounced elevations in plasma very long chain fatty acids as measured by gas-liquid chromatography (12)

Patients and normal volunteers, all males between the ages of 19 and $45 \mathrm{yr}$, had no abnormalities of serum cholesterol or triglyceride levels, were receiving regular diets, and had fasted overnight before $10 \mathrm{ml}$ of venous blood was drawn into a heparinized Vacutainer tube and immediately placed on ice. All subsequent steps in preparation of erythrocyte membranes were performed at $4^{\circ} \mathrm{C}$. After a 10 -min centrifugation at $900 \mathrm{~g}$, the serum was removed and the cell pellet was washed twice with $10 \mathrm{ml}$ of phosphate-buffered saline (PBS), pH 7.4, being centrifuged each time at $900 \mathrm{~g}$ for $10 \mathrm{~min}$. The cell pellet was then resuspended in $30 \mathrm{ml}$ of $5 \mathrm{mM}$ phosphate buffer at $\mathrm{pH} 8.0$ and recentrifuged. The lysed cell pellet was subsequently washed repeatedly in the $5 \mathrm{mM}$ phosphate buffer until all visible traces of hemoglobin had been removed. These membranes were suspended in PBS, $\mathrm{pH} 7.1$, at a concentration of $33 \mu \mathrm{g}$ protein $/ \mathrm{ml}$ (13).

1,6-Diphenylhexatriene (DPH, Aldrich Chemical Co., Inc., Milwaukee, WI) was dissolved in tetrahydrofuran (Waters Associates, Inc., Milford, MA) at a concentration of $464 \mu \mathrm{g} / \mathrm{ml}$ before being dispersed in PBS, pH 7.1, to provide a final concentration of $2 \mu \mathrm{M}$. This was sparged with nitrogen gas to remove traces of tetrahydrofuran before use. The membrane suspension was incubated with buffer $\pm D P H$ in a $1: 1$ ratio at $25^{\circ} \mathrm{C}$ for $1 \mathrm{~h}$ in a final vol of $3 \mathrm{ml}$. Each membrane sample was incubated in triplicate and subjected to polarization analysis by measuring the emission fluorescence in an Aminco fluorescence spectrophotometer (SPF$500)$. Fluorescence polarization $(P)$ was calculated according to the equation: $P=\left(I_{V}-T \cdot I_{H}\right) /\left(I_{V}+T \cdot I_{H}\right)$, where $I_{V}$ and $I_{H}$ are the relative fluorescence intensities measured at an angle $90^{\circ}$ to the incident beam with the emission polarization in the vertical and horizontal positions, respectively, and $T$ $=I_{\mathrm{V}} / I_{\mathrm{H}}$ measured with the excitation polarization in the horizontal position (14). The intensities of the fluorescence by membranes incubated without DPH, although relatively insignificant, were substracted from the corresponding values obtained with DPH before calculation of each value of fluorescence polarization.

Packed, washed erythrocytes $(0.25 \mathrm{ml})$ were extracted with $5 \mathrm{ml}$ of chloroform/methanol (2:1) for $24 \mathrm{~h}$. The total lipid extract was then submitted to a Folch extraction, methanolized, and fatty acid methyl esters purified by thin-layer chromatography essentially as described (12) except thinlayer plates were developed in hexane/ether/acetic acid (90:10:1). Fatty acid methyl esters were dissolved in 100 $\mu \mathrm{l}$ of hexane. Fatty acid analysis was performed on a Hewlett-Packard 5710 gas chromatograph (Hewlett-Packard Co., Palo Alto, CA) in splitless mode using a 12-m long OV101A capillary column. Initial column temperature was $120^{\circ} \mathrm{C}$. After $2 \mathrm{~min}$, the column temperature was increased $16^{\circ} \mathrm{C}$ / min to $280^{\circ} \mathrm{C}$ and maintained at that temperature for $2 \mathrm{~min}$. Fatty acid methyl ester peaks were identified by comparison with appropriate known standards. All analyses were done in duplicate. Fatty acid composition was expressed as a percentage of total fatty acids eluting from the column with a retention time equal to or greater than palmitic acid.

\section{RESULTS}

Erythrocyte membranes were obtained from 9 affected patients and 10 unaffected normal volunteers. Each time a patient or volunteer was studied or re-

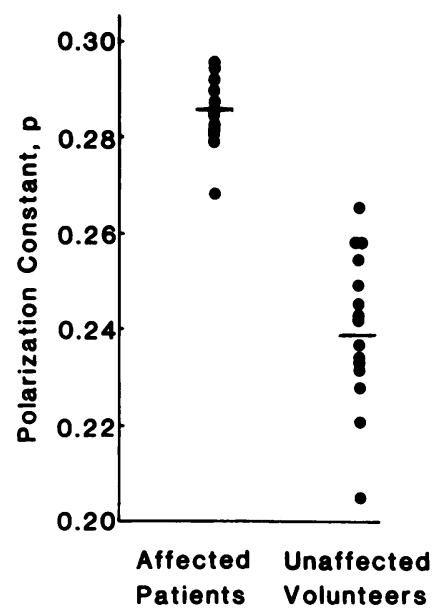

Figure 1 Polarization constant of membranes obtained from patients having $\operatorname{AMN}(n=7)$ or $\operatorname{ALD}(n=2)$ vs. normal controls $(n=10)$. Each point represents the average of six or nine individual determinations on each person. The average of all values of the polarization for both groups, denoted by the horizontal bars, are significantly different $(P$ $<0.001$ ).

studied, the polarization constant was calculated from the average of six or nine separate measurements using that blood sample. One patient was studied on four occasions yielding $P$ values of $0.287,0.268,0.281$, and 0.290 , while four of the volunteers were studied more than once. The average value of fluorescence polarization constant $\boldsymbol{P}$ for affected individuals was $0.286 \pm 0.012(\mathrm{SD})$, compared with a value of $0.239 \pm 0.020$ for unaffected volunteers. (Fig. 1). The difference between these two groups was significant at the probability is less than 0.001 level with the ranges of $0.268-0.295$ and $0.205-0.265$ for patients and volunteers, respectively.

Gas-liquid chromatography of total erythrocyte lipids demonstrated 1.9-, 1.6-, and 1.3-fold increases in C25:0, C26:0, and C27:0 saturated fatty acids, respectively (Table I). The ratios of the amounts of these fatty acids to those of the C22:0 were also elevated over the values found in erythrocytes obtained from normals.

\section{DISCUSSION}

Fatty acid analysis of total erythrocyte lipids from patients with ALD and AMN showed an increase in very long chain fatty acids, confirming a prior report of elevations in the ratio of C26:0 to C22:0 in erythrocyte sphingomyelin (11). The magnitude of very long chain fatty acid accumulation in erythrocyte membranes of patients is less than that reported in brain, adrenal, nerve, cultured muscle, or plasma (68,12 ). One of the apparent effects of this fatty acid 
TABLE I

Erythrocyte Fatty Acid Content

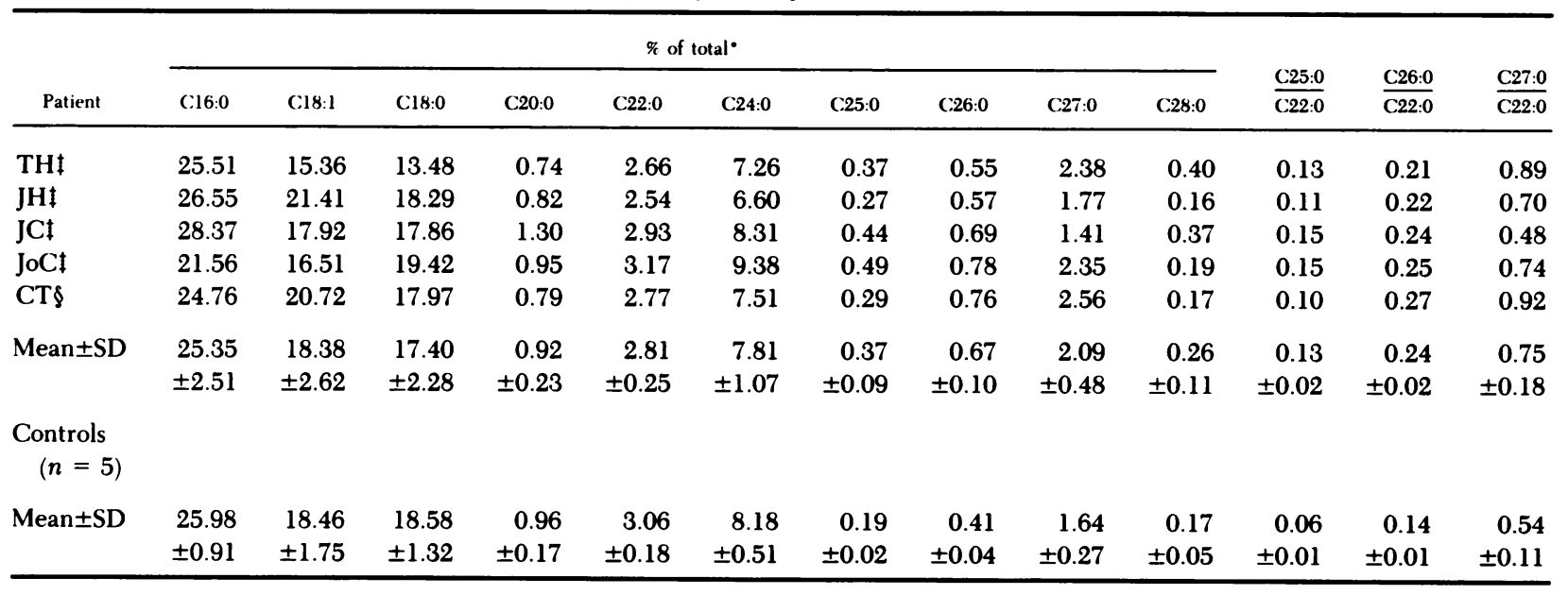

- Expressed as percentage of total fatty acids with retention time greater than or equal to that of C16:0.

$\downarrow$ AMN patient.

\$ ALD patient.

accumulation is to increase the index of microviscosity, $P$, of erythrocyte membranes as shown in this study. Increasing fatty acid chain length of artificial membranes results in increasing microviscosity (15), consistent with our findings in ALD and AMN erythrocyte membranes. Cholesterol, protein, and decreased percentage of unsaturated fatty acids all serve to make biological membranes more rigid (16-21).

Previous animal studies have demonstrated that exclusion of unsaturated fatty acids from the diet increases hepatic membrane microviscosity while concomitantly decreasing both the number of prolactin receptors and their induction $(22,23)$. Other studies have shown an inverse relationship between membrane microviscosity and number of prolactin receptors (24). A decrease in membrane microviscosity by any means, either in vivo or in vitro, caused an increase in the number of such receptors $(25,26)$. Other investigators have obtained supportive evidence correlating the number of membrane-associated receptors with changes in membrane microviscosity (27-30). The similarity of transition temperatures observed in studies on ACTH binding and fluorescence polarization using human adrenal membranes prompted one group to suggest that ACTH receptors were modulated by changes in the membrane fluidity (31). Given the knowledge that the abnormal accumulation of very long chain fatty acids occurs in the adrenals and testes as well as the erythrocytes and that such changes alter the membrane microviscosity, we propose that the endocrine dysfunction in ALD and AMN is due to an altered ability of target tissues to respond to their trophic stimuli perhaps because of decreased number of hormone receptors, and that prolonged unresponsiveness to such stimuli may result in irreversible atrophy of those organs.

While erythrocytes do not represent such a hormone-responsive tissue, they do provide an easily accessible source of membrane. Assays of such cells very likely reflect the result of a general lipid dysfunction within these patients. While biopsy of the major organs affected would provide a definitive analysis of the membrane abnormality within the living patients, assay of the erythrocyte membrane microviscosity by fluorescent polarization techniques is less invasive. Although this technique provides a rapid and straightforward means for differentiating between affected and nonaffected patients, it should not be used as a substitute for direct measurement of plasma very long chain fatty acids in the definitive diagnosis of these diseases.

These results suggest that abnormalities in membrane fluidity associated with very long chain fatty acid accumulation could account for at least part of the pathophysiology of ALD and AMN.

\section{ACKNOWLEDGMENTS}

We appreciate the assistance of Mr. Steve Cheff in performing the fluorescence polarization studies. We appreciate the assistance of Dr. T. Takakuwa of the Northern Virginia Training Center, Fairfax, VA, Dr. H. W. Moser of the J. F. Kennedy Institute, Baltimore, MD, and Dr. D. L. Loriaux of the National Institute of Child Health and Human Development, Bethesda, MD in obtaining the patients who participated in this study. 


\section{REFERENCES}

1. Schaumburg, H. H., J. M. Powers, C. S. Raine, K. Suzuki, and E. P. Richardson, Jr. 1975. Adrenoleukodystrophy. Arch. Neurol. 32:577-591.

2. Griffin, J. W., E. Goren, H. Schaumburg, W. K. Engel, and D. L. Loriaux. 1977. Adrenomyeloneuropathy: a probable variant of adrenoleukodystrophy. Neurology. 27:1107-1113.

3. Davis, L. E., R. D. Snyder, D. N. Orth, W. E. Nicholson, M. Kornfeld, and D. F. Seelinger. 1979. Adrenoleukodystrophy and adrenomyeloneuropathy associated with partial adrenal insufficiency in three generations of a kindred. Am. J. Med. 66:342-347.

4. O'Neill, B. P., L. C. Marmion, and E. R. Feringa. 1981. The adrenoleukomyeloneuropathy complex: expression in four generations. Neurology. 31:151-156.

5. Schaumburg, H. H., J. M. Powers, C. S. Raine, P. S. Spencer, J. W. Griffin, J. W. Prineas, and D. M. Boehme. 1977. Adrenomyeloneuropathy: a probable variant of adrenoleukodystrophy. Neurology. 27:1114-1119.

6. Igarashi, M., H. H. Schaumburg, J. Powers, Y. Kishimoto, E. Kolodny, and K. Suzuki. 1976. Fatty acid abnormality in adrenoleukodystrophy. J. Neurochem. 26:851-860.

7. Menkes, J. H., and L. M. Corbo. 1977. Adrenoleukodystrophy: accumulation of cholesterol esters with very long chain fatty acids. Neurology. 27:928-932.

8. Askanas, V., J. McLaughlin, W. K. Engel, and B. T. Adornato. 1979. Abnormalities in cultured muscle and peripheral nerve of a patient with adrenomyeloneuropathy. N. Engl. J. Med. 301:588-590.

9. Kawamura, N., A. B. Moser, H. W. Moser, T. Ogino, K Suzuki, H. Schaumburg, A. Milunsky, J. Murphy, and Y. Kishimoto. 1978. High concentration of hexacosanoate in cultured skin fibroblast lipids from adrenoleukodystrophy patients. Biochem. Biophys. Res. Commun. 82:114-120.

10. Moser, H. W., A. B. Moser, N. Kawamura, J. Murphy, K. Suzuki, H. Schaumburg, and Y. Kishimoto. 1980. Adrenoleukodystrophy: elevated C26 fatty acid in cultured skin fibroblasts. Ann. Neurol. 7:542-549.

11. Tsuji, S., M. Suzuki, T. Ariga, M. Sekine, M. Kuriyama, and T. Miyatake. 1981. Abnormality of long-chain fatty acids in erythrocyte membrane sphingomyelin from patients with adrenoleukodystrophy. J. Neurochem. 36:1046-1049.

12. Moser, H. W., A. B. Moser, K. K. Frayer, W. Chen, J. D. Schulman, B. P. O'Neill, and Y. Kishimoto. 1981. Adrenoleukodystrophy: increased plasma content of saturated very long chain fatty acids. Neurology. 31:12411249.

13. Lowry, O. H., N. J. Rosebrough, A. L. Farr, and R. J. Randall. 1951. Protein measurement with the Folin phenol reagent. J. Biol. Chem. 193:265-275.

14. Chen, R. E., H. Edelhoch, and R. J. Steiner. 1969. Physical Principles and Techniques of Protein Chemistry, S. J. Leach, editor. Academic Press, Inc., New York. Part A, 171-240.

15. Chapman, D., and D. F. H. Wallach. 1968. Biological Membranes, D. Chapman, editor. Academic Press, London. 125-202.
16. Vanderkooi, J., S. Fischkoff, B. Chance, and R. A. Cooper. 1974. Fluorescent probe analysis of the lipid architecture of natural and experimental cholesterolrich membranes. Biochemistry. 13:1589-1595.

17. Shinitzky, M., and M. Inbar. 1976. Microviscosity parameters and protein mobility in biological membranes. Biochim. Biophys. Acta. 433:133-149.

18. Cooper, R. A. 1977. Abnormalities of cell-membrane fluidity in the pathogenesis of disease. N. Engl. J. Med. 297:371-377.

19. Cogan, U., M. Shinitzky, G. Weber, and T. Nishida. 1973. Microviscosity and order in the hydrocarbon region of phospholipid and phospholipid cholesterol dispersions determined with fluorescent probes. Biochemistry. 12:521-528.

20. Lentz, B. R., Y. Barneholz, and T. E. Thompson. 1976. Fluorescence depolarization studies of phase transitions and fluidity in phospholipid biolayers. Biochemistry. 15:4521-4537.

21. Shinitzky, M., and P. Henkart. 1979. Fluidity of cell membranes: current concepts and trends. Int. Rev. Cytol. 60:121-147.

22. Knazek, R. A., and S. C. Liu. 1981. Effects of dietary essential fatty acids on murine mammary gland development. Cancer Res. 41:3750-3751.

23. Knazek, R. A., and S. C. Liu. 1979. Dietary essential fatty acids are required for maintenance and induction of prolactin receptors. Proc. Soc. Exp. Biol. Med. 162:346-350.

24. Dave, J. R., R. A. Knazek, and S. C. Liu. 1981. Prolactin modifies the fluidity of rat liver membranes. Biochem. Biophys. Res. Commun. 100:45-51.

25. Dave, J. R., R. A. Knazek, and S. C. Liu. 1981. Arachidonic acid, bradykinin, and phospholipase $A_{2}$ modify, both prolactin binding capacity, and fluidity of mouse hepatic membranes. Biochem. Biophys. Res. Commun. 103:727-738.

26. Knazek, R. A., S. C. Liu, J. R. Dave, R. J. Christy, and K. A. Keller. 1981. Indomethacin causes a simultaneous decrease of both prolactin binding and fluidity of mouse liver membranes. Prostaglandins Med. 6:403-411.

27. Neufeld, N. D., and L. Corbo. 1982. Increased cord monocyte insulin receptors: association with membrane lipid properties. The Endocrine Society, 64th Annual Meeting, San Francisco, CA. 1026A, 336.

28. Neufeld, N. D., and L. Corbo. 1982. Increased fetal insulin receptors and changes in membrane fluidity and lipid composition. Am. J. Physiol. 243:E246-E250.

29. Strulovici, B., H. R. Lindner, M. Shinitzky, and U. Zor. 1981. Elevation of apparent membrane viscosity in ovarian granulosa cells of follicle-stimulating hormone. Biochim. Biophys. Acta. 640:159-168.

30. Yuli, I., A. Tomonaga, and R. Snyderman. 1982. Chemoattractant receptor functions in human polymorphonuclear leukocytes are divergently altered by membrane fluidizers. Proc. Nat. Acad. Sci. USA. 79:5906-5910.

31. Bashford, C. L., S. J. Harrison, G. K. Radda, and Q. Mehdi. 1975. The relation between lipid mobility and the specific hormone binding of thyroid membranes. Biochem. J. 146:473-479. 